\title{
Professioneel leren: wat is het en hoe bevorderen we het?
}

\author{
S. Bolhuis
}

\section{Samenvatting}

Professioneel leren: Toenemende kennis en ontwikkelingen in gezondheidszorg en samenleving stellen hoge eisen aan het professioneel leren. Artsen leren in hun beroepsuitoefening lang niet altijd gestructureerd en expliciet, zoals in het onderwijs. Informeel leren, door ervaring en sociale interactie, vindt vaak weinig bewust plaats en wordt beinvloed door de praktijkcultuur. Net zo min als onderwijs leidt het automatisch tot beter handelen. De kwaliteit van de praktijk is belangrijk en moet daarom steeds gezamenlijk kritisch onderzocht worden. Expliciteren en kritisch reflecteren op impliciete gewoontes en opvattingen is nodig voor: het inwijden van nieuwelingen, samenwerking en het voorkomen van ongewenste gewoontevorming.

Definitie van professioneel leren: Het organiseren en kritisch-reflectief integreren van ervaringsleren, sociaal leren en theoretisch leren, zowel individueel als gezamenlijk, gericht op zowel de verbetering van het professionele handelen als van de handelingssituatie. Het professionele handelen is zowel doel als bron van leren. Het collectieve niveau moet betrokken worden bij het denken over professioneel leren en handelen.

Naar professioneel leren: uitdagingen voor het medisch onderwijs: Een goede voorbereiding van studenten op professioneel leren vereist een innige verstrengeling van praktijk en formeel leren. Studenten moeten leren om theorie en praktijk reflectief op elkaar te betrekken. Opleiders, in hun functie als rolmodel voor professioneel gedrag, expliciteren hun gedrag, stimuleren studenten tot het stellen van kritische vragen en geven feedback, ook op het leergedrag. Als opleiders niet zelf kritisch reflecteren, leren studenten het ook niet. Zowel individuele opleiders als de organisaties zijn verantwoordelijk voor een goede leerwerkomgeving waarin studenten dit voorbeeldgedrag over zullen nemen als onderdeel van hun toekomstig beroep. (Bolhuis S. Professioneel leren: wat is het en hoe bevorderen we het? Tijdschrift voor Medisch Onderwijs 2002;21(4):172-182.)

\section{Waarom professioneel leren: externe beweegredenen}

Wat betekent 'professioneel' leren? De term professioneel kan zowel feitelijk als normatief worden opgevat. In feitelijke zin gaat het om het leren dat is gerelateerd aan de professie, aan het beroep van arts. In normatieve zin duidt de kwalificatie 'professioneel' erop dat leren als onderdeel van de beroepsuitoefening wenselijk is. Daarbij suggereert 'professioneel' dat zulk leren een zekere kwaliteit moet hebben, dat het voldoet aan bepaalde eisen zoals die aan professionele beroepsbeoefenaars mogen worden gesteld. In deze paragraaf wordt besproken welke externe argumenten worden aangevoerd om de wenselijkheid van professioneel leren te onderstrepen. Het feitelijke leren in de beroepspraktijk komt verderop in dit artikel aan de orde.

In tal van publicaties en ook in het oude en nieuwe Raamplan wordt geconcludeerd dat een professionele beroepsuitoefening vraagt om levenslang leren. ${ }^{1-3} \mathrm{De}$ argumenten zijn in willekeurige volgorde 
als volgt samen te vatten. Allereerst verouderen medische kennis en vaardigheden snel door de explosieve toename van onderzoek en technologie - en de beschikbaarheid daarvan. Ook ontstaan nieuwe ethische en juridische vraagstukken. Ten tweede leidt de grote toename van kennis tot een groeiende wirwar van subspecialismen, wat ironisch genoeg weer leidt tot de behoefte aan generalisten, een gemeenschappelijke basis in de opleiding en meer samenwerking tussen artsen en andere zorgverleners. Ten derde is er steeds meer nieuwe kennis die (opnieuw) duidelijk maakt dat ziekte en gezondheid fenomenen zijn die met tal van andere zaken samenhangen, van voedingspatronen, werksituatie, wonen en vrijetijdsbesteding tot de omgang met problemen en verdriet in de persoonlijke levenssfeer. Ten vierde verandert de relatie tussen artsen en patiënten door diverse factoren, zoals het toegenomen opleidingsniveau bij een deel van de bevolking, de beschikbaarheid van medische kennis (en pseudo-kennis) op het internet, de vergrijzing, een multiculturele bevolking en een toegenomen consumentisme vergezeld van het gevoel dat geluk en gezondheid te koop zijn. Ten vijfde neemt de druk toe om efficiency en effectiviteit in de zorg op te voeren om de kosten beheersbaar te houden. Al deze verschuivingen brengen mee dat voortdurend nieuwe eisen aan de competenties van artsen worden gesteld. Dat betekent niet alleen dat nieuwe dingen bijgeleerd moeten worden, maar ook dat eigen vertrouwde opvattingen en gewoontes, waar nodig, afgeleerd moeten kunnen worden.

De verschuivingen in eisen komen ook tot uitdrukking in diverse herdefiniëringen van de taken en rollen die artsen in de samenleving moeten vervullen. Een voorbeeld is te vinden bij Prideaux et al., die onder de professionele rol van artsen zes rollen samenbrengen: de 'medisch deskundige', die zijn kennis up to date houdt; de 'communicator', die zich ervan bewust is dat een goede communicatie met patiënten, collega's en andere zorgverleners essentieel is voor een goede gezondheidszorg; de 'samenwerker', voor wie multiprofessionele samenwerking een vanzelfsprekende praktijk is; 'de manager', die in staat is tot prioriteiten stellen in de besteding van tijd en middelen; de 'health advocate', die opkomt voor gezondheid in de maatschappelijke context; en de 'scholar', die steeds zoekt naar de beste onderbouwing voor eigen handelen. ${ }^{4}$ Interessant is dat Prideaux et al. elk van deze rollen óók bespreken als rolmodel voor goed klinisch onderwijs. In hun ogen sluiten de eisen die de zorg stelt én het opleiden van aankomende artsen in de praktijk naadloos bij elkaar aan.

\section{Motivatie vanuit de beroeps- uitoefening: interne beweegredenen}

De externe argumenten voor het blijvend leren tijdens de professionele beroepsuitoefening worden pas werkzaam als ze voldoende weerklank vinden bij interne beweegredenen van artsen. De genoemde factoren en beschreven rollen dienen de beroepsmotivatie aan te spreken. Men zal zich erdoor aangesproken kunnen voelen als dit past in het eigen beroepsbeeld en bij de eigen identiteit als arts. De motivatie om optimale zorg voor de patiënt na te streven moet samengaan met het steeds opnieuw geboeid worden door de vraag wat die optimale zorg is en de wil en het vermogen om zich daar telkens weer in te verdiepen. ${ }^{5}$ De innerlijke 'drive' om het eigen professionele handelen voortdurend op peil te houden, het openstaan voor nieuwe vraagstukken, willen leren van eigen ervaringen, bereid zijn om kritisch na te denken over eigen praktijk en over informatie van buitenaf, kortom de 'drive' 
voor professioneel leren, hangt samen met het beroepsbeeld en de zelfwaardering in relatie tot dat beroepsbeeld. Leerprocessen tijdens de opleiding en (vooral de eerste jaren van) de beroepsuitoefening dragen belangrijk bij aan de ontwikkeling van het beroepsbeeld en de beroepsidentiteit. Leren voor en in een beroep hangt nauw samen met identiteitsvorming. 67 Medisch onderwijs dient er dan ook mede op gericht te zijn om 'lerende professionals' op te leiden.

\section{Allerlei vormen van leren in de professionele beroepsuitoefening}

De in het voorgaande besproken overwegingen ondersteunen de normatieve betekenis van 'professioneel leren', in die zin dat ze aangeven waarom het gewenst is dat artsen als professionele beroepsbeoefenaars blijven leren. Wat is de feitelijke stand van zaken bij het professionele leren van artsen? Er is intussen het nodige onderzoek gedaan bij artsen en andere beroepsgroepen naar de wijze waarop zij in en door hun werk hun professionele competentie ontwikkelen en - meer algemeen - leren. ${ }^{8-10}$ Hierbij vallen drie samenhangende punten op: 1) de diversiteit van leeractiviteiten en van de participatie daarin, 2) de invloed van de sociale context en 3) het impliciete karakter van veel leren in het kader van de beroepsuitoefening.

Allereerst is er sprake van een grote diversiteit aan activiteiten en van verschillen tussen professionals in het soort activiteiten waarin zij participeren en de mate waarin zij dat doen. Er zijn allerlei formele activiteiten (cursussen, nascholing), die tegenwoordig in verband met het behouden van de registratie als arts een nieuw gewicht krijgen. Daarnaast, en zeker zo invloedrijk, zijn er echter talrijke informele leeractiviteiten, die meer of minder direct samenhangen met het werk. Becher beschrijft bijvoorbeeld naast het formele nascholingscircuit een groot aantal activiteiten, die hij rangschikt in vier globale categorieën van informeel leren. ${ }^{11}$ Dat is ten eerste het bekende 'bijblijven' op basis van tijdschriften en andere informatie. Ten tweede, zo merkt hij op, "gaan verrassend veel van zijn informanten uitgebreid in op hoe zij leren in de praktijk": door ervaring, zien van anderen, eigen handelen. Ten derde vindt veel leren plaats door praktijkgerelateerde activiteiten: over de praktijk schrijven, onderwijs geven, onderzoek doen en dergelijke. Een vierde belangrijke categorie is het interpersoonlijke leren door netwerken, monitoren of coachen, raadplegen van experts met een specifieke deskundigheid (specialisten) of met collega's overleggen en besprekingen voeren met als doel professionele kennis zowel te vergroten als te delen.

Het is duidelijk dat de sociale context voor de diversiteit en participatie in het informele leren belangrijk is. In de sociale context van de praktijk horen sommige activiteiten er vanzelfsprekend bij - of niet. Er is bijvoorbeeld sprake van geregeld overleg, er is een traditie van intercollegiale consultatie, er wordt betrokkenheid bij onderwijs verwacht, et cetera. Leren in de sociale context is deels relatief expliciet. Informanten, zoals de geïnterviewden bij Becher, zullen vaak het eerst melding maken van deze expliciete, intentionele manieren van professioneel leren. Desondanks vond Becher dat er 'verrassend veel' over het leren door ervaring werd gemeld. In ander onderzoek is sterker gefocust op het weinig bewuste, impliciete leren, dat als het ware een bijeffect is van het participeren in de sociale omgeving. ${ }^{12}$ Het leren is hier een direct gevolg van het meemaken, ervaren, observeren en zelf meedoen aan de gebruikelijke gang van zaken in een bepaalde prak- 
tijk. Die praktijk heeft zich in de loop van de tijd ontwikkeld: de gewoontes, opvattingen, omgang met elkaar, werkwijze maken deel uit van de lokale cultuur. Het impliciete karakter van een deel van de leerprocessen binnen de beroepsuitoefening brengt met zich mee dat deze leerprocessen en -resultaten vaak weinig worden opgemerkt. Daarbij komt dat leren in de praktijk een krachtige vorm van leren blijkt.

\section{Leren in de praktijk vergeleken met leren in onderwijssettings}

Tot hun spijt moeten opleiders nogal eens vaststellen dat zij hun studenten weliswaar zorgvuldig bepaalde dingen hebben geleerd (bijvoorbeeld hoe je een bepaald onderzoek bij patiënten uitvoert), maar dat die studenten, als zij in de praktijk met een andere werkwijze kennismaken, die meestal zonder meer overnemen. Leren leidt niet altijd tot het gewenste handelen in de praktijk en (kennismaken met) handelen in de praktijk leidt (ook) tot leren. Er zijn enkele belangrijke verschillen tussen het leren in de praktijk en het leren dat domineert in onderwijs, opleiding en nascholing. ${ }^{13}$

- In educatieve settings wordt over het algemeen uitgegaan van de volgorde: eerst buiten de context, theoretisch leren en eventueel 'droog oefenen', dan in de praktijk toepassen. Wat in de praktijk wordt geleerd is echter direct gekoppeld aan het handelen: men leert het handelen door participatie, door deel te nemen aan het handelen en de leerresultaten zijn impliciet opgeslagen in het handelen.

- Om in educatieve settings te leren moet men zich bewust inspannen, terwijl er in de praktijk door ervaring en sociale interactie altijd geleerd wordt, ook zonder een bewuste leerinspanning en zonder educatieve interventies. Er moet dus altijd rekening mee worden gehouden dat er in de praktijk geleerd wordt en wat de effecten daarvan zijn.

- Wat in educatieve settings wordt geleerd, is daartoe expliciet vertaald in woorden en symbolen (bijvoorbeeld in leerboeken en opdrachten). Dat maakt een 'terugvertaling' nodig naar de betekenis in de praktijk. Wat in de praktijk wordt geleerd wordt voor een belangrijk deel terloops, niet gemedieerd, overgebracht. Het wordt daardoor vaak ook weinig of niet bewust verworven en is niet zonder inspanning in woorden beschikbaar.

- Bij de keuze van leerstof in de medische opleiding en nascholing wordt sterk gesteund op het wetenschappelijke karakter (evidence based medicine). Bij het handelen in de praktijk spelen echter ook allerlei andere factoren een rol en sluipen gewoontes in die geen voorwerp zijn van kritisch onderzoek.

- Tegelijk kan worden geconstateerd dat wat in educatieve settings wordt geleerd relatief gemakkelijk wordt vergeten of terzijde geschoven als niet relevant, terwijl wat in de praktijk wordt geleerd een grote mate van vanzelfsprekendheid krijgt. De praktijk is overweldigend 'echt' en is daarmee een buitengewoon overtuigende, krachtige leeromgeving.

- Terwijl in educatieve settings de motivatie moet worden ontleend aan een verhoopt nut in de toekomst en/of elders, komt de motivatie in de praktijk voort uit het directe beroep dat de situatie doet op de (aanstaande) arts. Daarbij spelen onder andere een rol: de noodzaak tot handelen, de wens om dat overeenkomstig het eigen beroepsbeeld te doen én de behoefte om erbij te horen.

Als het gaat om het professionele handelen moet worden geconcludeerd dat de praktijk het vaak wint van de theorie. De professionele beroepsuitoefening is niet 
alleen een individueel-autonome kwestie. Het handelen wordt beïnvloed door de cultuur van de organisatie, dat wil zeggen door de gebruikelijke praktijk en de daarin besloten waarden en normen van de betreffende organisatie (ziekenhuisafdeling, huisartspraktijk, et cetera).

\section{Leidt professioneel leren altijd tot beter handelen?}

Het lijkt bijna vanzelfsprekend dat professioneel leren erop gericht zou moeten zijn om de professionele beroepsuitoefening te ondersteunen, te verbeteren of aan te vullen. Toch is het de vraag of die link wel automatisch gelegd kan worden. Wat mensen bijvoorbeeld in opleiding en nascholing hebben geleerd, brengen ze niet altijd in praktijk. Het handelen en de ervaring in de praktijk werpen hun eigen leerresultaten af: het opdoen van ervaring door eigen handelen en door sociale interactie op de werkplek levert spontane leerprocessen op. Of het professionele leren in de zin van het feitelijke leren in de beroepsuitoefening altijd tot beter handelen leidt, hangt dus mede af van de kwaliteit van de omgeving, preciezer: de kwaliteit van de praktijk in een bepaalde omgeving.

Daarmee wordt de vraag of professioneel leren wordt gericht op verbetering van het professionele handelen een vraag waarop ook de organisatie waarbinnen die arts werkt in belangrijke mate antwoord geeft. De vraag of professioneel leren gericht zou moeten zijn op verbetering is dus een vraag die niet alleen een individuele arts zichzelf kan stellen, maar ook een vraag die professionele beroepsbeoefenaars zich gezamenlijk moeten stellen en die niet alleen op het individuele niveau, maar zeker ook op het niveau van de organisatie moet worden beantwoord. ${ }^{8} 1415$ Daarvoor is inzicht nodig in het feitelijke leren in de beroepsuitoefening: in de sociaal-culturele aard van zowel de inhoud als het proces van leren en de impliciete aard van veel leren op de werkplek. Inzicht bij de betrokkenen in hun eigen impliciete leren en handelen vraagt om regelmatig expliciteren.

\section{Expliciteren ter bevordering van professioneel leren}

Het informele, impliciete leren in de praktijk heeft een grote betekenis voor de competentieontwikkeling. De aandacht voor impliciete kennis komt voor een deel uit het onderzoek naar de kennis van experts (in vergelijking met nieuwelingen). Polanyi sprak al in 1967 over het belang van 'tacit knowledge' in het handelen van experts: de kennis en vaardigheden die door ervaring zijn opgedaan, als het ware in het handelen zijn opgeslagen en essentieel zijn in het snel en deskundig handelen dat typerend is voor de expert. ${ }^{16}$ Hoewel de discussie over de precieze aard van deze 'tacit knowledge' of 'knowing-inaction' eigenlijk pas recent echt is begonnen, is er wel overeenstemming over het belang ervan voor professioneel handelen. ${ }^{17}$

Naast de voordelen van impliciete leerresultaten zijn er verschillende redenen waarom expliciteren nuttig kan zijn. ${ }^{13}$

- Voor nieuwelingen wordt het stapsgewijs gaan delen in kennis van experts vergemakkelijkt als de expert expliciteert: op grond van welke overwegingen en factoren doet hij/zij nu dit in deze situatie? Zijn er alternatieven mogelijk of is dit de enige goede keuze?

- Voorts vereist een goede samenwerking dat informatie, overwegingen, intuïties, plannen en ervaringen worden gedeeld met anderen, zodat zij kunnen meedenken in de gezamenlijke zorg. Veel problemen in de zorg en in de communicatie met de patiënt ontstaan doordat wederzijdse aannames niet worden geëxpliciteerd. 
- Ook als een team op elkaar is ingespeeld en dus gezamenlijke 'tacit knowledge' heeft ontwikkeld blijft expliciteren van belang. Als vanzelfsprekende aannames te sterk overheersen staat dat het signaleren van afwijkingen van het bekende in de weg en dus een adequate benadering daarvan. Dat geldt voor een team en op het individuele niveau. Het is uit de psychologie bekend dat de waarneming van de wereld wordt gefilterd door het eigen referentiekader. Van het bekende afwijkende informatie wordt gemakkelijk over het hoofd gezien of - ten onrechte - ingepast in het bekende.

- In een organisatie ontstaat in de loop van de tijd een cultuur: routines, oplossingen voor problemen en daarbij horende opvattingen. Het regelmatig expliciteren en kritisch evalueren van schijnbaar vanzelfsprekende routines en opvattingen is nuttig om mogelijk ongewenste gewoontevorming bijtijds te doorbreken.

Het is een gegeven dat informeel, impliciet leren plaatsvindt en dit kan óók betekenen: het niet verder ontwikkelen van competenties of het voortzetten van incompetent gedrag, het insluipen van verkeerde gewoontes, blijven hangen in verouderde routines, bestendigen van weinig patiëntvriendelijke omgangsvormen, et cetera. De kracht van de praktijk als leeromgeving impliceert dat nieuwelingen vaak in de bestaande cultuur worden meegenomen. De praktijk wordt gevormd door deels wisselende collega's uit andere disciplines en zorgverleners uit andere beroepsgroepen. Door hun verantwoordelijkheden en gezag hebben artsen een grote invloed op de gang van zaken in de praktijk. Daarnaast hebben zij vaak gedurende periodes in hun loopbaan, formeel of informeel, een rol in de opleiding van nieuwe collega's. Genoeg reden om professioneel leren niet alleen op het indivi- duele niveau, maar ook gerelateerd aan de gezamenlijke cultuur te stimuleren. ${ }^{14}$

\section{Samenvattend: een definitie van professioneel leren}

In overeenstemming met het voorgaande wordt de volgende definitie van professioneel leren voorgesteld: het organiseren en kritisch-reflectief integreren van ervaringsleren, sociaal leren en theoretisch leren, zowel individueel als gezamenlijk, gericht op zowel de verbetering van het professionele handelen als van de handelingssituatie. 18 Het professionele handelen staat centraal, zoals in figuur 1 is te zien. Professioneel leren betreft een breed scala aan zowel formele als informele leeractiviteiten. Hierin kunnen vier categorieën worden onderscheiden. De eerste twee zijn het leren door ervaring (ervaring door het meemaken en ondergedompeld zijn in een omgeving en door eigen handelen) en het leren door sociale interactie (door alledaagse conversatie, uitwisseling van informatie, samenwerken, probleem- en conflicthantering). Deze leeractiviteiten vinden 'vanzelf' plaats door participatie in de praktijk. Een derde categorie is het 'theoretische leren' (gemedieerde informatieverwerking, studie en oefenen van vaardigheden buiten de directe praktijk). De diverse vormen van leren hebben elk hun sterke en zwakke kanten zoals elders is uiteengezet. ${ }^{18} \mathrm{Bij}$ elk van de drie is het van belang om de relatie met het handelen kritisch-reflectief te onderzoeken en, waar nodig, te verbeteren. Daartoe is een vierde categorie nodig: kritisch-reflectief integreren, waarbij de verschillende vormen van leren met elkaar in verband worden gebracht, op elkaar worden betrokken en kritisch getoetst. Kritisch-reflectief leren betreft het zonodig expliciteren, analyseren en op waarde onderzoeken van: a) eigen referentiekader, impliciete gewoontes en opvattingen en het eigen 
professionele handelen, b) externe informatie (in boeken, tijdschriften, internet, mondelinge communicaties), c) de impliciete gewoontes en opvattingen in de eigen omgeving (cultuur) en ook d) eigen professionele leergewoontes.

Verschillende vormen van leren moeten niet alleen aan het toeval worden overgelaten, maar ook worden georganiseerd. Niet alleen in de formele settings van opleiding en nascholing kan leren worden georganiseerd, maar ook in het werk zelf. Allerlei momenten in het werk (overleg, overdracht, verslaglegging, et cetera) zijn zelf al leersituaties en kunnen vaak als leersituaties worden verbeterd.

Het organiseren van leren dient zowel individueel als gezamenlijk te worden ondernomen. Het bewaken en verbeteren van het professionele handelen is een blijvend doel. Professioneel handelen wordt niet alleen beschouwd als een indvidueel-autonome aangelegenheid, maar tevens als een kwestie van gezamenlijke cultuur. Een professionele beroepsuitoefening vraagt om het zich voortdurend bewust zijn (expliciteren) van de gebruiken en achterliggende opvattingen in de handelingssituatie, vanuit de vraag of de gebruikelijke praktijk (nog steeds) de meest wenselijke is. Kritische reflectie wordt dus ook gericht op de praktijkcultuur (figuur 1.).

Figuur 1. Professioneel leren in relatie tot handelen.

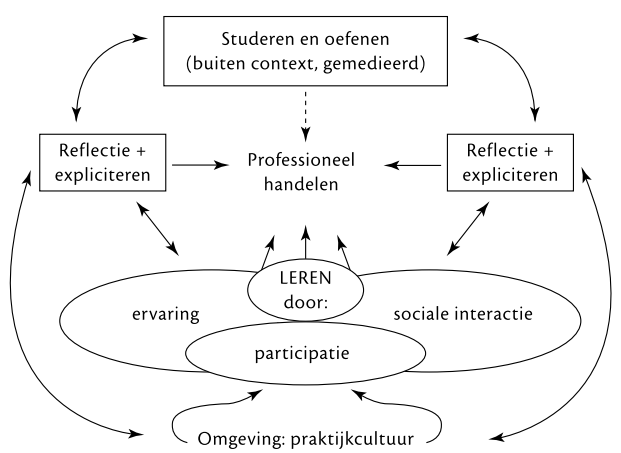

In de hier geschetste relatie tussen professioneel leren en handelen in de praktijk ligt een reeks van uitdagingen voor opleiding, nascholing en beroepspraktijk besloten. Het professionele handelen heeft een centrale plaats: als doel, maar ook als bron van leren. Kritisch expliciteren en reflecteren begeleidt het leren en heeft als het ware een voortdurend evaluerende functie. Informele en formele leerprocessen en resultaten moeten met elkaar in verband worden gebracht. Essentieel is het betrekken van het collectieve niveau in het denken over professioneel leren (en handelen).

\section{Naar professioneel leren: uitdagingen voor medisch onderwijs}

Als blijvend professioneel leren een belangrijke eis is aan hedendaagse en toekomstige artsen, is de vraag hoe het medisch onderwijs studenten daarop voorbereidt. Hoe leren studenten leren? Dat leren ze allereerst door de ervaring die zij opdoen met leren in de opleiding, dus met de wijze waarop het leren in de opleiding is georganiseerd. Let wel, niet door de uitleg die studenten van hun opleiders krijgen ('verteld worden hoe het moet'), maar door de manier waarop leren in de opleiding functioneert, door wat wordt beloond of niet beloond ('merken hoe het werkt'). De eerste uitdaging voor de opleiding is dus om het leren zoveel mogelijk zó te organiseren dat het een afspiegeling is van het gewenste professionele leren. Niet alleen de medische faculteiten maar ook de academische en geaffilieerde ziekenhuizen dienen zich bewust te zijn van hun uitermate belangrijke modelfunctie. ${ }^{5}$

De relatie tussen leren en handelen is vanouds een hot topic in alle vormen van beroepsonderwijs en ook in de medische opleiding. Een innige verstrengeling van enerzijds leren in de praktijk en anderzijds formeel leren van theorie en vaardigheden, zo vroeg mogelijk in het curricu- 
lum, zou wenselijk zijn om van meet af aan professioneel leren te leren beoefenen. Dat hoeft niet beperkt te blijven tot het vrij onbewuste model van leren als een 'black box'. Integendeel, het is ook gewenst om bewust aandacht te besteden aan de ervaringen die worden opgedaan door en met verschillende manieren van leren in relatie tot het werk. Medisch onderwijs dient te bevorderen dat studenten zich bewust zijn van verschillende formele en informele leerprocessen en deze in samenhang kunnen hanteren.

De rol die opleiders vervullen is vierledig. - Allereerst staan zij model voor professioneel gedrag, inclusief professioneel leren. Dat medische studenten opleiders als model zien en daarbij eigen voorkeuren hebben is geen nieuws. ${ }^{19}$ De mate waarin de praktijk als leeromgeving werkzaam is, ook zonder dat daarin bewuste keuzes worden gemaakt, blijft echter onderschat. Deze 'opleidingsfunctie' werkt ook als noch opleiders noch studenten daarbij stilstaan. Door zich bewust onderzoekend en kritisch reflectief op te stellen geven opleiders een voorbeeld van meer gewenst professioneel leren. Als opleiders zich bewust zijn van hun functie als model voegen ze daar het volgende aan toe.

- Opleiders expliciteren regelmatig hun modelgedrag: leggen uit, geven overwegingen, plaatsen hun handelen in een context, benoemen zekerheden en onzekerheden, geven aan welke vragen het handelen omringen - en maken daarbij duidelijk met behulp van welke leerstrategieën zij in verschillende situaties te werk gaan.

- Opleiders stimuleren vervolgens studenten tot het zelf ontwikkelen van professioneel leervermogen, door opdrachten te geven en vragen te stellen die de beroepsmotivatie prikkelen en door aandacht voor de leeractiviteiten van stu- denten. Professioneel leren aanmoedigen kan bijvoorbeeld betekenen: helpen expliciteren van individuele en gezamenlijke ervaringen, stimuleren om (diverse) anderen te raadplegen, kritische vragen stellen en signaleren welke leeractiviteiten tot verbeterd professioneel handelen bijdragen.

- Opleiders geven tot slot ook nog feedback die zowel corrigerend als belonend is. Uit de feedback van opleiders maken studenten op wat belangrijk is. Als professioneel leren belangrijk is, moet feedback dus ook het leerproces betreffen.

Langzamerhand is algemeen bekend dat het leren van studenten sterk wordt gestuurd door toetsing en evaluatie, of anders gezegd: door wat er wordt beloond. ${ }^{20}$ 21 Studenten lezen daar terecht aan af wat er werkelijk belangrijk wordt gevonden voor hun opleiding tot arts. Dit is een ijzeren gegeven als het gaat om de keuze en het ontwikkelen van nieuwe evaluatievormen. Als professioneel leren behoort tot de beroepscompetentie moeten formatieve en summatieve evaluatie daar mede op worden gericht. Het verwerven van competenties voor professioneel leren heeft ook consequenties voor de manieren waarop wordt getoetst. Zelfevaluatie en intercollegiale evaluatie zijn immers belangrijke elementen van blijvend professioneel leren en zullen dus ook in de opleiding moeten worden aangeleerd.

Studenten moeten vanaf het begin worden aangemoedigd om theorie en praktijk reflectief op elkaar te betrekken. Opleiders hebben een belangrijke begeleidende en coachende rol bij het aanmoedigen van kritische reflectie. ${ }^{22}$ Ook het reflectief analyseren van ongeplande en onvoorziene leereffecten (effecten van informeel leren) heeft een belangrijke plaats. Om studenten aan te moedigen tot kritische reflectie is het modelgedrag van opleiders een sterk leermiddel. Andersom gezegd: 
bij modelgedrag waarin geen kritische reflectie is te bespeuren, kan dat ook niet van studenten worden verwacht. Kritische reflectie betreft het omgaan met de wetenschappelijke literatuur en met het eigen professioneel handelen, maar ook de professionele omgeving. Voor het bieden van een goede leerwerkomgeving is de organisatie (ziekenhuis, afdeling, huisartspraktijk) verantwoordelijk, niet alleen individuele opleiders. Individuele professionals zijn op hun beurt echter medeverantwoordelijk voor de organisatie en de daar gebruikelijke gang van zaken, de praktijkcultuur. Studenten zullen leren om die verantwoordelijkheid te zien als onderdeel van hun toekomstig beroep als zij desbetreffend voorbeeldgedrag meemaken.

\section{Literatuur}

1. Medisch-specialistische zorg in de toekomst. Zoetermeer: Raad voor de Volksgezondheid en Zorg; 2001.

2. Het medisch opleidingscontinuüm. Projectplan voor een toekomstverkenning. Utrecht: Koninklijke Nederlandse Maatschappij der Geneeskunst (KNMG); 2000.

3. Metz JCM, Verbeek-Weel AMM, Huisjes HJ, editors. Raamplan 2001 Artsopleiding. Bijgestelde eindtermen van de artsopleiding. Nijmegen: Mediagroep; 2001.

4. Prideaux D, Alexander H, Bowerd A, Dacre J, Haist S, Jolly B, et al. Clinical teaching: maintaining an educational role for doctors in the new health care envirionment. Med Educ 2000;34:820-6.

5. Holdrinet RSG. Dokters gevraagd. Een reflectie op wetenschap en zorg met betrekking tot medisch onderwijs. Nijmegen: Katholieke Universiteit Nijmegen; 1999.

6. Lave J, Wenger E. Situated learning. Legitimate peripheral participation. Cambridge: Cambridge University Press; 1991.

7. Slotnick HB. How doctors learn: Education and learning across the medical-school-to-practice trajectory. Acad Med 2001;76(10):1013-26.

8. Bolhuis S, Simons RPJ. Leren en werken. 1st ed. Deventer: Kluwer; 1999.

9. Klarus R. Bekwaamheden erkennen. Een studie naar modellen en procedures voor leerwegonafhankelijke beoordeling van beroepsbekwaamheden. Nijmegen; 1998.
10. Onstenk J. Ontwikkelen van bekwaamheden tijdens het werk. In: Poell R, Kessels J, editors. Human resource development. Organiseren van het leren. Groningen: Samson; 2001. p. 285-300.

11. Becher T. Professional practices: Commitment and capability in a changing environment. New Brunswick, N.J.: Transaction Publishers; 1999.

12. Eraut M. Developing professional knowledge and competence. London: Falmer Press; 1994.

13. Bolhuis S. Leren en veranderen bij volwassenen. Een nieuwe benadering. 2nd ed. Bussum: Coutinho; 2001.

14. Frankford DM, Patterson MA, Konrad TR. Transforming practice organizations to foster lifelong learning and commitment to medical professionalism. Acad Med 2000;75(7):708-17.

15. Nutley SM, Davies HTO. Developing organizational learning in the NHS. Med Educ 2001;35:35-42.

16. Polanyi M. The tacit dimension. New York: Doubleday; 1967.

17. Eraut M. Non-formal learning, implicit learning and tacit knowledge in professional work. In: Coffield F, ed. The necessity of informal learning. Bristol: The Policy Press; 2000. p. 12-31.

18. Bolhuis S, Doornbos A. Leren op de werkplek. Advies t.b.v. het pilot-project zij-instroom van vakmensen als leraar in het vmbo. Zoetermeer: Ministerie van OC\&W; 2000.

19. Stegeman JH. Goed voorbeeld doet goed volgen: een zoektocht naar rolmodellen in het praktisch klinisch onderwijs. Ned Tijdschr Geneeskd 2001;145(9):431-4.

20. Dochy F, Segers M, Buehl M. The relation between assessment practices and outcomes of studies: The case of research on prior knowledge. Review of Educational Research 1999;69(2):14589.

21. Vleuten CPM van der, Driessen EW. Toetsing in probleemgestuurd onderwijs. Groningen: Wolters-Noordhoff; 2000.

22. Holdrinet RSG, Oeseburg B, Bulte J, Laan R, redactie. Handleiding Begeleiding Co-assistenten. Nijmegen: UMC St Radboud; 2000.

De auteur:

Dr. S. Bolhuis is als onderwijskundige werkzaam bij de Afdeling Onderwijsontwikkeling en Onderzoek van het Onderwijsinstituut, UMC St. Radboud, Nijmegen.

Correspondentieadres:

Dr. S. Bolhuis, UMC Sint Radboud Nijmegen, Onderwijsinstituut, Onderwijsontwikkeling en Onderzoek, 224 KTC, Postbus 9101, 6500 HB Nijmegen,S.Bolhuis@ped.kun.nl. 


\section{Summary}

Professional learning: Knowledge growth and other developments in health care and society necessitate lifelong professional learning. Doctors learn in practice in several ways, which are often not structured and explicit, unlike learning in formal education. Non-formal learning, through experience and social interaction, often happens rather unconsciously and influenced by the culture of practice. Like education, it does not guarantee improved performance. The quality of practice is a crucial factor, which should be subject to shared critical examination. Implicit learning and actions should be made explicit, so that novices may learn from experts, collaboration is improved and mindless habits are prevented.

Definition of professional learning: Learning through experience and social interaction, and theoretical learning are integrated by critically reflecting on one's personal frame of reference, implicit habits and opinions in the working environment and personal professional learning habits. This is done individually and collaboratively, since the shared culture of professional practice is both the goal and source of professional learning.

Towards professional learning: challenges for medical education: Learning in formal settings and in practice should be intertwined to prepare students for professional learning. Students should learn to reflexively integrate theory and practice. As role models of professional conduct and learning, teachers explain their actions, encourage students to ask critical questions, and give feedback, also on learning behaviour. When teachers do not reflect critically, students will not learn to do so. Both individual teachers and organizations are responsible for a positive learning environment, providing positive role models to be incorporated by students in their future professional practice. (Bolhuis $S$. Professional learning: what is it and how can we promote it? Dutch Journal of Medical Education 2002;21(4):173-182.) 